\title{
Relationship between movement dysfunctions and sports injuries according to gender of youth soccer player
}

\author{
Ki-Hoon Lim, Tae-Beom Seo, Young-Pyo Kim* \\ Department of Kinesiology, College of Natural Science, Jeju National University, Jeju, Korea
}

The purpose of this study is to investigate relationship between movement dysfunctions and sports injuries according to gender of youth soccer player. Thirty-eight middle school soccer players participated in this study and they were divided into male $(n=19)$ and female $(n=19)$ groups. The Functional Movement Screen (FMS) and the Quadricepsangle ( $Q$-angle) during single-leg squat were analyzed for identifying imbalance and asymmetry of the body, and sports injury questionnaire was examined for 6 months after FMS test. The number of sports injuries did not show significant difference between youth male and female soccer athletes. In FMS results, the scores of overhead squat, hurdle step, in-line lunge, shoulder mobility, active straight leg raise, and rotary stability and the total scores were no significant differences between gender, but the score for the trunk stability push-up was significantly higher in male group than female group. There was no significant difference of $\mathrm{Q}$-angle values between the left and right legs, but $\mathrm{Q}$-angle value between youth male and female groups significantly showed interaction. Therefore, the present data suggested that FMS and Q-angle during single-leg squat might be indicators to predict and/or prevent sports injury in youth male and female soccer players.

Keywords: Movement dysfunction, Sports injury, Functional Movement Screen, Q-angle, Youth soccer player

\section{INTRODUCTION}

Soccer is the most popular sport around the world, but it is a vigorous sport event with frequent exposure to injuries, from adolescents to adults (Dahlstrom et al., 2012).

Sports injuries are caused by various intrinsic risk factors such as injury history, body components, and joint flexibility (Bahr and Holme, 2003; Gomez et al., 1998; Krivickas and Feinberg, 1996). Since these intrinsic factors cannot be manipulated voluntarily, sports injuries of athletes have been predicted and prevented by evaluating movement dysfunction (Bond et al., 2019; Plisky et al., 2006).

Movement dysfunction means that muscle and joint movements are not normal while performing a specific motion or this motion is completed by compensation of another muscle and joint. In the past, sports scientists recognized that movement dysfunction in athletes could lead to sports injury during the training and competition, but there were no enough equipment and methods to investigate movement dysfunction. In the 2000s, various evaluation tools were presented to assess the relationship between sports injuries and movement dysfunction, of which Functional Movement Screen (FMS) developed by Cook et al. (2006a) was recommended as the most effective way to predict sports injury of athletes. Kramer et al. (2019) studied relationship between FMS and athletic performance and found a significant correlation in FMS scale and physical performance test such as standing long jump, vertical jump, and agility, suggesting a standardized assessment to predict sports injury and performance of athletes.

In addition to FMS for injury prevention strategy, the analysis of the Quadriceps-angle (Q-angle) during the single-leg squat is also one of the methods to examine knee damages including the muscle, ligament, and tendon (Hewett et al., 2006). Many previous studies suggested that changes in the Q-angle value in singleleg squat test increased the occurrence of sports injury along with movement dysfunction of athletes (Hewett et al., 2005; Zazulak et al., 2005; Zeller et al., 2003).
${ }^{*}$ Corresponding author: Young-Pyo Kim (iD https://orcid.org/0000-0001-6662-1393 Department of Kinesiology, College of Natural Science, Jeju National University, 102 Jejudaehak-ro, Jeju 63243, Korea

E-mail: kimyp@jejunu.ac.kr

Received: September 2, 2020 / Accepted: September 21, 2020
This is an Open Access article distributed under the terms of the Creative Commons Attribution Non-Commercial License (https://creativecommons.org/licenses/by-nc/4.0/) which permits unrestricted non-commercial use, distribution, and reproduction in any medium, provided the original work is properly cited. 
In studies on FMS and sports injury in soccer players, Chalmers et al. (2018) investigate the relationship between FMS asymmetry and number of games played before first injury and reported to be closely associated with a significant increase in prospective injury risk (Grygorowicz et al., 2013; Miller and Susa, 2019; Sprague et al., 2014).

With these research findings, FMS and Q-angle during single-leg squat tests are absolutely necessary for prediction and prevention of sports injuries in soccer players. But almost all previous studies on asymmetry and physical performance in soccer have mainly focused on senior athletes, and there are few studies on gender in adolescence soccer players. Therefore, the purpose of this study was to investigate the relationship among FMS, Q-angle, and sports injuries according to gender of youth soccer player.

\section{MATERIALS AND METHODS}

\section{Participants}

The participants in this study were 38 youth soccer players. As shown in Table 1, all participants were allocated to the male group $(n=19)$ and the female group $(n=19)$. Before beginning the measurement, participants were informed about study orally and they submitted their written informed consent to researchers. And this research was conducted ethically according to international guidelines.

\section{Body composition}

Height and body weight were measured in light clothing and without shoes using JENIX (DS-103M, Dong San Jenix, Seoul, Korea), and body composition was measured by Inbody 720 (Inbody 720 , Inbody, Seoul, Korea) to confirm the \% body fat.

\section{Sports injury questionnaire}

To find out the frequency of sports injury in athletes, we modified the questionnaire developed by Bond et al. (2019), and Finch

Table 1. The characteristics of the subjects

\begin{tabular}{lrrr}
\hline Variable & Male $(\mathrm{n}=19)$ & Female $(\mathrm{n}=19)$ & Mean $\pm S D$ \\
\hline Age $(\mathrm{yr})$ & $14.58 \pm 0.51$ & $14.47 \pm 0.51$ & $14.52 \pm 0.50$ \\
Height $(\mathrm{cm})$ & $168.58 \pm 7.08$ & $162.68 \pm 3.80$ & $165.63 \pm 6.35$ \\
Weight $(\mathrm{kg})$ & $59.55 \pm 9.91$ & $54.02 \pm 5.48$ & $56.78 \pm 8.38$ \\
$\%$ Fat $(\%)$ & $15.38 \pm 3.39$ & $22.97 \pm 4.14$ & $19.17 \pm 5.35$ \\
Career $(\mathrm{yr})$ & $6.47 \pm 0.84$ & $4.47 \pm 0.84$ & $5.47 \pm 1.30$ \\
\hline
\end{tabular}

Values are presented as mean \pm standard deviation (SD).

$\%$ Fat, body fat percentage. and Staines (2018). This questionnaire is categorized into various parts of the body, and the left and right injuries are also identified to predict muscle imbalance in athletes. After FMS assessment, all subjects participated in the survey to identify sports injuries that induced during the 6 months.

\section{FMS assessment}

To examine the imbalance and asymmetry of the body, we applied FMS assessment to youth soccer players. FMS consisted of seven movement tests including overhead squat, hurdle step, inline lunge, shoulder mobility, active straight leg raise, trunk stability push-up, and rotary stability. Three professional trainers performed the FMS test, and for the reliability of the measurement, a video was taken during the measurement.

\section{Analysis of Q-angle during single-leg squat}

To investigate the Q-angle in single-leg squat, it was analyzed using two cameras and a dartfish motion analysis program (Dartfish Live v.5.5, Dartfish, Fribourg, Switzerland). Markers were attached to the reference points needed for analysis such as the anterior superior iliac spine (ASIS), the center of the patella, and the tibial tuberosity. Knee extension and flexion exercises were performed within the range of $0^{\circ}-60^{\circ}$ joint motion, Q-angle (Escamila et al., 2009) and Q-angle measured at $60^{\circ}$ of knee flexion 3 times and then the average value was obtained.

\section{Statistical analysis}

PASW Statistics ver. 18.0 (SPSS Inc., Chicago, IL, USA) was used to determine difference of the number of sports injury and movement dysfunction according to gender of youth soccer players. An independent $t$-test was applied to compare the differences between the two groups. All values are expressed as mean \pm standard deviation. $P<0.05$ was considered significant.

\section{RESULTS}

\section{Difference in the number of sports injuries according to gender}

The number of sports injuries between youth male and female soccer athletes is shown in Table 2. Youth male soccer group showed

Table 2. The number of sports injuries according to the gender (number)

\begin{tabular}{lcccc}
\hline Variable & Male & Female & $t$ & $P$-value \\
\hline Sports injuries & $2.15 \pm 0.24$ & $2.47 \pm 1.16$ & 32.894 & 0.453 \\
\hline
\end{tabular}

Values are presented as mean \pm standard deviation. 
Table 3. Functional Movement Screen (FMS) scales according to the gender (score)

\begin{tabular}{lcccc}
\hline Variable & Male & Female & $t$ & $P$-value \\
\hline Overhead squat & $1.68 \pm 0.48$ & $1.94 \pm 0.40$ & 1.833 & 0.075 \\
Hurdle step & $1.95 \pm 0.40$ & $1.84 \pm 0.37$ & 0.832 & 0.411 \\
In-line lunge & $1.89 \pm 0.32$ & $1.95 \pm 0.23$ & 0.588 & 0.560 \\
Shoulder mobility & $2.32 \pm 0.75$ & $2.37 \pm 0.60$ & 0.239 & 0.812 \\
Active straight leg raise & $2.05 \pm 0.23$ & $2.32 \pm 0.67$ & 1.617 & 0.115 \\
Trunk stability push-up & $2.00 \pm 0.58$ & $1.42 \pm 0.51$ & 3.284 & $0.002^{*}$ \\
Rotary stability & $1.89 \pm 0.32$ & $1.95 \pm 0.23$ & 0.588 & 0.560 \\
Total score & $13.79 \pm 1.36$ & $13.79 \pm 1.47$ & 0.001 & 0.998 \\
\hline
\end{tabular}

Values are presented as mean \pm standard deviation. ${ }^{*} P<0.05$.

the result in a higher number of sports injuries than youth female soccer group, but there is no significant difference between two groups.

\section{Difference in FMS scores according to gender}

FMS scores between youth male and female soccer athletes are shown in Table 3. There were no significant differences in the values of overhead squat, hurdle step, in-line lunge, shoulder mobility, active straight leg raise, rotary stability, and total scores between two groups. However, trunk stability push-up variable showed significantly higher result in male group compared to female group.

\section{Difference in Q-angle during single-leg squat values according to gender}

The values of Q-angle in single-leg squat between youth male and female soccer athletes are shown in Table 4. We confirmed significant interaction in values of the left Q-angle between youth male and female groups $(F=7.601, P=0.007)$. The female group showed lower values of $\mathrm{Q}$-angle in the right leg compared to the left leg.

\section{DISCUSSION}

Movement dysfunction is an important indicator of sports injury through imbalance and asymmetry in adult athletes, suggesting that FMS and Q-angle are the most well-known measurement methods to predict sports injury in the training and competition (Kramer et al., 2019; Warren et al., 2018). Thus, we analyzed FMS and Q-angle in single-leg squat movement to youth male and female soccer players, which can instantly examine the dysfunction in the field.

Athletic performance is influenced by several factors including
Table 4. Q-angle values according to the gender (degree)

\begin{tabular}{lcccc} 
Variable & Male & Female & $t$ & $P$-value \\
\hline Right & $26.42 \pm 5.56$ & $28.79 \pm 6.97$ & 1.160 & 0.254 \\
Left & $26.81 \pm 4.71$ & $31.71 \pm 5.50$ & 2.944 & $0.006^{*}$ \\
$t$ & 0.410 & 2.569 & & \\
$P$-value & 0.686 & $0.019^{*}$ & & \\
\hline
\end{tabular}

Values are presented as mean \pm standard deviation.

${ }^{*} P<0.05$.

maximum strength, jumping, sprinting, agility, and balance capabilities. Among various assessment tools to predict body imbalance and asymmetry, FMS is the most popular way in the sports field and it is composed of a 4-point scale $(0=$ pain with pattern regardless of quality, $1=$ unable to perform pattern, $2=$ perform pattern with compensation, and $3=$ perform pattern as described) for each of 7 movements. In previous studies related to FMS, Shojaedin et al. (2014) reported that FMS might help screen musculoskeletal injury in university level athletes, and Chapman et al. (2014) suggested the positive relationship between FMS and competitive performance in elite track and field athletes. On the contrary, Dorrel et al. (2015) mentioned that the FMS is not an appropriate field test for predicting risk rate of sports injury and athletic performance. It is still controversial that FMS represents sports injury and performance of athletes. In the present study, we investigated 7 items of FMS, and represented that the only trunk stability push-up test showed significant difference between male and female groups and it was higher in the male group than in the female group ( $t=3.284, P=0.002$ ). Trunk stability push-up test is closely associated with core stabilization (Cook et al., 2006b), and the hip adductor and rotator muscles, abdominus, erector spinae muscle, and quadratus lumborum muscle that control core functions are relatively higher in male athletes than in female basketball players (Leetun et al., 2004). These findings in previous studies support the reasons why female athletes score low on the trunk stability push-up test, and we believe that training programs to improve core strength and functions should be applied since adolescent.

Q-angle is referred to as the quadriceps angle and it is the angle between two intersection lines from the patella center to the ASIS and the patella center to the tibia tuberosity (Pantano et al., 2005). We confirmed that total values of Q-angle during single-leg squat were significantly lower in male group compared to female group $(t=2.666, P=0.009)$. These differences are because female athletes had larger range of motion of dorsiflexion, ankle eversion, hip flexion, hip external rotation, and lateral trunk flexion during singleleg squat than male athletes (Zeller et al., 2003). Zazulak et al. 
(2005) demonstrated that women could have a lager Q-angle during single-leg squat through low electromyographic (EMG) activity of gluteus maximus and high EMG activity of rectus femoris compared to men. A larger Q-angle may lead to greater peak knee valgus during physical activity and then result in anterior cruciate ligament (ACL) damage over time (Pantano et al., 2005). In the clinical study on valgus and ACL strain reported by Bjordal et al. (1997), senior and junior female athletes were found to have 3 to 5 times higher incidence of ACL injury than male athletes (Engström et al., 1991).

Taken together, in FMS test according to gender of youth soccer players, female athletes should improve their relative upper extremity muscle strength and scapula stabilization from adolescents, considering that female athletes showed only higher values of trunk stability push-up movement than male athletes. Also, since female athletes have Q-angle values during single-leg squat, specific and scientific training programs to prevent the knee valgus must be performed from adolescence.

Therefore, our results provide evidence that FMS and Q-angle during single-leg squat might be indicators to predict and prevent sports injury in youth male and female soccer players.

\section{CONFLICT OF INTEREST}

No potential conflict of interest relevant to this article was reported.

\section{ACKNOWLEDGMENTS}

This work was supported by the 2020 Education, Research and Student Guidance Grant funded by Jeju National University.

\section{REFERENCES}

Bahr R, Holme I. Risk factors for sports injuries-a methodological approach. Br J Sports Med 2003;37:384-392.

Bjordal JM, Arnoy F, Hannestad B, Strand T. Epidemiology of anterior cruciate ligament injuries in soccer. Am J Sports Med 1997;25:341-345.

Bond CW, Dorman JC, Odney TO, Roggenbuck SJ, Young SW, Munce TA.

Evaluation of the Functional Movement Screen and a Novel Basketball Mobility Test as an injury prediction tool for collegiate basketball players. J Strength Cond Res 2019;33:1589-1600.

Chalmers S, Debenedictis TA, Zacharia A, Townsley S, Gleeson C, Lynagh M, Townsley A, Fuller JT. Asymmetry during Functional Movement Screening and injury risk in junior football players: a replication study.
Scand J Med Sci Sports 2018;28:1281-1287.

Chapman RF, Laymon AS, Arnold T. Functional movement scores and longitudinal performance outcomes in elite track and field athletes. Int J Sports Physiol Perform 2014;9:203-211.

Cook G, Burton L, Hoogenboom B. Pre-participation screening: the use of fundamental movements as an assessment of function - part 1. N AM J Sports Phys Ther 2006a;1:62-72.

Cook G, Burton L, Hoogenboom B. Pre-participation screening: the use of fundamental movements as an assessment of function - part 2. N AM J Sports Phys Ther 2006b;1:132-139.

Dahlstrom O, Backe S, Ekberg J, Janson S, Timpka T. Is "football for all" safe for all? Cross-sectional study of disparities as determinants of 1-year injury prevalence in youth football programs. PLoS One 2012; 7:e43795.

Dorrel BS, Long T, Shaffer S, Myer GD. Evaluation of functional movement screen as an injury prediction tool among active adult populations: a systematic review and meta-analysis. Sports Health 2015;7: 532-237.

Engström B, Johansson C, Törnkvist H. Soccer injuries among elite female players. Am J Sports Med. 1991;19:372-375.

Escamila RF, Zheng N, Macleod TD, Edwards WB, Imamura R, Hreljac A, Fleisig GS, Wilk KE, Moorman CT, Andrews JR. Patellofemoral joint force and stress during the wall squat and one-leg squat. Med Sci Sports Exerc 2009;41:879-888.

Finch CF, Staines C. Guidance for sports injury surveillance: the 20-year influence of the Australian Sports Injury Data Dictionary. Inj Prev 2018;24:372-380.

Gomez JE, Ross SK, Calmbach WL, Kimmel RB, Schmidt DR, Dhanda R. Body fatness and increased injury rates in high school football linemen. Clin J Sport Med 1998;8:115-120.

Grygorowicz M, Piontek T, Dudzinski W. Evaluation of functional limitations in female soccer players and their relationship with sports level - a cross sectional study. PLoS One 2013;8:e66871.

Hewett TE, Myer GD, Ford KR. Anterior cruciate ligament injuries in female athletes part 1, mechanisms and risk factors. Am J Sports Med 2006;34:299-311.

Hewett TE, Myer GD, Ford KR, Heidt RS, Colosimo AJ, McLean SG, Succop P. Biomechanical measures of neuromuscular control and valgus loading of the knee predict anterior cruciate ligament injury risk in female athletes a prospective study. Am J Sports Med 2005;33:492-501.

Kramer TA, Sacko RS, Pfeifer CE, Gatens DR, Goins JM, Stodden DF. The association between the functional movement screen ${ }^{\mathrm{TM}}$, Y-balance test, and physical performance tests in male and female high school athletes. Int J Sports Phys Ther 2019;14:911-919

Krivickas LS, Feinberg JH. Lower extremity injuries in college athletes: re- 
lation between ligamentous laxity and lower extremity muscle tightness. Arch Phys Med Rehabil 1996;77:1139-1143.

Leetun DT, Ireland ML, Willson JD, Ballantyne BT, Davis IM. Core stability measures as risk factors for lower extremity injury in athletes. Med Sci Sports Exerc 2004;36:923-934.

Miller JM, Susa KJ. Functional Movement Screen scores in a group of division IA athletes. J Sports Med Phys Fitness 2019;59:779-783.

Pantano KJ, White SC, Gilchrist LA, Leddy J. Differences in peak knee valgus angles between individuals with high and low Q-angles during a single limb squat. Clin Biomech 2005;20:966-972.

Plisky PJ, Rauh MJ, Kaminski TW, Underwood FB. Star Excursion Balance Test as a predictor of lower extremity injury in high school basketball players. J Orthop Sports Phys Ther 2006;36:911-919.

Shojaedin SS, Letafatkar A, Hadadnezhad M, Dehkhoda MR. Relationship between functional movement screening score and history of injury and identifying the predictive value of the FMS for injury. Int J Inj Contr Saf Promot 2014;21:355-360.

Sprague PA, Mokha GM, Gatens DR. Changes in functional movement screen scores over a season in collegiate soccer and volleyball athletes. J Strength Cond Res 2014;28:3155-3163.

Warren M, Lininger MR, Chimera NJ, Smith CA. Utility of FMS to understand injury incidence in sports: current perspectives. Open Access J Sports Med 2018;7:171-182.

Zazulak BT, Ponce PL, Straub SJ, Medvecky MJ, Avedisian L, Hewett TE. Gender comparison of hip muscle activity during single-leg landing. J Orthop Sports Phys Ther 2005;35:292-299.

Zeller BL, McCrory JL, Kibler WB, Uhl TL. Differences in kinematics and electromyographic activity between men and women during the single-legged squat. Am J Sports Med 2003;31:449-456. 